\title{
Ritualisation of Crisis Communication
}

\author{
Crowd-enabled responses \\ to the Stockholm terror attack on Twitter
}

\author{
Minttu Tikka
}

Media and Communication Studies, University of Helsinki, Finland

\begin{abstract}
Digital connectivity enables ordinary people to participate in the social construction of crises. This article explores the crisis responses of common people through the prism of ritual communication in the case of the 2017 Stockholm terror attack. The ritual approach has helped to produce a nuanced understanding of the social functions of patterned and performative communication in crises and conflicts. However, the crisis communication of ordinary people has remained understudied from the viewpoint of ritualisation. Drawing from digital media ethnography and content analysis of a Twitter feed created around the hashtag \#openstockholm, it is claimed that the ritualisation of crisis responses illustrates the active agency of ordinary people and contributes to ephemeral social cohesion.
\end{abstract}

Keywords: crisis, ritualisation, connective action, digital media ethnography, Twitter

\section{Introduction}

The communicative role of ordinary people in crises and disasters has inevitably changed in this era of a digital media environment. Instead of assuming the role of a passive audience trapped in the position of ritualised spectators (Chouliaraki, 2013), ordinary people can now participate in the construction of crises through the practices of crisis communication (e.g. Park \& Johnston, 2017). In this article, I investigate the crisis responses of citizens as ritualised practices in the case of the Stockholm terror attack in April 2017. In this situation, ordinary people, inspired by similar initiatives in the contexts of previous terror attacks in Europe, mobilised action on Twitter immediately after the attack under the hashtag \#openstockholm. I argue that the communication around the hashtag \#openstockholm served as a ritualised crisis communication practice that was enabled by digital connectivity.

In today's acute crisis events, such as terror attacks and disasters (Bruns \& Hanusch, 2017), connected individuals represent electronic eyes and ears, reconfiguring the traditional relations of communicative power (Coombs, 2012; Cottle, 2014; Holmgreen, 2015; Sumiala et al., 2018; United Nations Foundation, 2011). Instead of the

Tikka, Minttu (2019). Ritualisation of Crisis Communication: Crowd-enabled responses to the Stockholm terror attack on Twitter in Nordicom Review 40 (2019) 1, pp. 105-120. doi:10.2478/ nor-2019-0006. 
traditional news media that previously played a key role in the creation of modernity's shared worlds, much of the public sense of the world is now created on and through digital media platforms. Through interactivity, social media have changed the space for social action and created a boundless reserve for human action (Couldry, 2012). According to Dhiraj Murthy, the concept of social media is commonly "conceived of as a medium wherein 'ordinary' people in ordinary social networks (as opposed to professional journalists) can create user-generated 'news'" (Murthy, 2012: 1061). This view draws attention to the transformation in the roles of ordinary people in the sense that they are not only audiences but also a crucial part of the production and content of the media (Turner, 2010). In line with this notion, I argue that "ordinary" people, who have no professional role in the management, rescue or reporting efforts of acute crisis events, play increasingly performative and constitutive roles in them. Thus, crisis communication is no longer limited to the realms of journalism, politics, business and humanitarian aid, as various forms of digital media permit other social actors, such as ordinary people affected by a crisis, to engage in "connective action" (Bennet \& Segerberg, 2013). This digital connectiveness allows ordinary people to mobilise without the coordination of any public or private organisations and to have a profound impact on the crises themselves in terms of their organisation, development, outcomes and social implications (e.g. Hjarvard et al., 2015; Mortensen, 2015; Pantti \& Tikka, 2014; Pantti et al., 2012).

Since 2010, scholars (e.g. Coombs, 2012; Givoni, 2016; Holmgreen, 2015; Jin et al., 2014; Schwarz et al., 2016; Takahashi et al., 2015) and the disaster relief community (e.g. International Federation of Red Cross and Red Crescent Societies, 2013) have acknowledged the proliferation of public voices and the growing presence of ordinary people in the field of crisis communication. However, crisis and disaster researchers have placed a strong and long-standing emphasis on top-down approaches, whereby organisations, institutions and authorities are the centre of attention (Holmgreen, 2015; Tierney, 2007). In turn, the bottom-up research on other types of actors and voices remains fragmented in different disciplines in the literature, such as the social sciences, emergency management and information technology (e.g. Crowe, 2012; Murthy \& Gross, 2017; Starbird \& Palen, 2010). Nevertheless, with the growth of social media, it has become concretely viable to engage with the bottom-up approach and to study "the everyday practices of social actors and the cultural forms naturally emerging from them, in and through the Internet", as Caliandro (2018: 553) phrased it.

Thus, in this article, the crisis communication of ordinary people on Twitter is studied through the prism of ritual communication. Ritual research has been widely undertaken to consider the role of communicative action in acute crisis events (Morse, 2018; Rothenbuhler, 2010; Sumiala, 2013). It has helped to produce an understanding of the social functions of patterned, performative and symbolic forms of communication related to the cohesion and/or disruption of societies and communities in times of crisis (Grimes, 2011; Rothenbuhler, 2010; Sumiala et al., 2018; Sumiala \& Tikka, 2011). However, the crisis communication of ordinary people has remained understudied from the viewpoint of ritualisation. Taking into consideration the immediate and intense participation of social media users in crises (e.g. Bruns \& Hanusch, 2017) and the established theoretical notion that rituals shape crises and conflicts (Grimes, 2011; Sumiala, 2013), it seems vital to study the crisis communication of ordinary people as 
ritualised practices and to ask how those practices shape the social dynamics of acute crisis events.

To fill this gap between the ritual approach and the notion of digitally connected ordinary people in acute crisis events, the theoretical grounding on rituals in this article draws on the literature of disaster sociology, media and communication studies and anthropology. In addition, Bennet and Segerberg's (2013) idea of connective action is applied to broaden the existing research theoretically and to advance our comprehension of the ritualisation of crisis communication of ordinary people in the digital media environment. I argue that the ritual approach helps us to see beyond the multiplicity and heterogeneity of digitally mediated responses to crises. Consequently, the ritual approach facilitates a nuanced understanding of the profound social purposes of the communicative performances of ordinary people amidst acute crisis events. Three questions will be asked: 1) How are the crisis communication practices of ordinary people ritualised in the digital age? 2) What are the social functions of these ritualised practices? 3) How do they shape the roles of ordinary people?

In the following, I will first provide a case description of the Stockholm terror attack and then offer a theoretical outline of rituals in crisis events and discuss the role of digitally connected ordinary people. Next, I will move on to the empirical analysis of the communicative practices related to \#openstockholm. The case and the material were collected and analysed in two empirical phases. In the first phase, the case of the Stockholm terror attack was traced through digital media ethnography, which is a methodological approach that allows the researcher to conduct real-time observations of digital communication patterns. In the second phase, the primary empirical data, which consist of a Twitter feed created during the acute phase around \#openstockholm, are examined through qualitative content analysis. Drawing on these analyses, I examine first the ritual process and second the social functions of this ritualisation. Third, I extend these insights to assess the roles of ordinary people. Finally, I conclude by reflecting on how the ritualised crisis response of ordinary people shaped the public experience of the terror attack.

\section{The terror attack and its response}

The terror attack in Stockholm began some minutes before 3 p.m. on Friday, 7 April 2017. The perpetrator hijacked a truck and accelerated down a pedestrian street in Drottninggatan, killing five and injuring at least 15 people. The attack ended as the truck rammed into the corner of an Åhlens City department store and caught fire at 2:56 p.m. The perpetrator fled on foot, leaving behind an array of dead and injured victims and shocked eyewitnesses. Information and images of the truck attack immediately started to spread on social media, and they were shared and commented on by authorities, journalists and ordinary citizens.

As the medical staff treated the injured victims and the police launched a massive security operation, rumours of reported shootings started to circulate on traditional and social media. For example, at 3:17 p.m., a Swedish national public TV broadcaster reported live that it had received testimonies of gunfire near the site of the attack. The local news media, TV4, Dagens Nyheter and Expressen also reported on the shootings (Mediepodden, 2017). The news of an ongoing rampage caused growing anxiety and insecurity among the people. 
An hour after the assault, the authorities had put the city centre in lockdown by stopping public transportation via train, metro and bus lines, evacuating Stockholm's central railway station and number of shopping locations and closing the Swedish parliament. As members of the police isolated the attack area with barricades, they urged people to go home and avoid crowds, using loudspeakers and Twitter. However, most people lacked a safe place nearby as well as a means to exit the city centre and travel home other than walking.

In response to the plight of people stranded in the city, some Stockholmers started on Twitter to offer their homes as places of shelter to those in need. As Jenny Nguyen, a Swedish law student, received news of the attack, she opened Twitter and saw several tweets offering help. While she noticed that these messages were not coordinated in any way, she tweeted at 4:44 p.m., "Could we collect all who are opening their doors in Stockholm under one hashtag '\#openstockholm'?” Her first message was in Swedish, and her second, making the same suggestion, was in English. The hashtag \#openstockholm quickly attracted massive engagement on Twitter. Thus, even though she did not previously have a considerable following or influence on Twitter, her message initiated a mobilisation that thousands joined. According to the quantitative analysis by Al-Saqaf and Christenssen (2017), in the \#openstockholm feed, there were over 40,000 original tweets and 86,000 messages with retweets in five days, and the majority, approximately 20,000, were released within the first 10 hours.

The acute phase of the crisis ended on the same evening at approximately 8 p.m., when the perpetrator was apprehended in a suburb north of Stockholm and public transportation received permission from the authorities to resume services (The Local, 2017).

\section{Theoretical framework: rituals in crises}

Rituals play ambiguous roles in events of terror, violence and disruption. Scholars of rituals have asserted that ritual processes have transformative power; they can shape crises, and they may either escalate or mediate conflicts (Grimes, 2011; Sumiala, 2013). It can be said that crisis events are heavily and complexly ritualised. The literature on rituals carries several definitional ambiguities, but they can be characterised as prescribed and repeated action. In addition, the functional dimension is emphasised by asking what a ritual does (Grimes, 2011; Sumiala, 2013). Johanna Sumiala (2013), for example, maintained that the presence of death engenders rituals that organise our social world in crises. Furthermore, rituals are usually formalised: "there are ways to do it, ways not to do it" (Grimes, 2011: 12). Through formalisation, rituals elevate events and make them symbolically significant (Grimes, 2011). Thus, when studying rituals, the focus of attention is on the repeating patterns of communicative practices and on the social functions related to this action. In the following, three focal perspectives on rituals in crisis are presented: media as a context of rituals, rituals as coping practices and the ritual roles of spectators.

\section{Media as a context of rituals}

The contemporary media environment provides a context in which crises and the related communicative rituals take place. Media rituals can be defined as a "recurring and pat- 
terned form of symbolic communication that allows us, through performance, to attach ourselves to the surrounding media-related world" (Sumiala, 2013: 9). Rituals performed in and via the media sphere in the midst of disruption have been studied widely, with a focus on traditional media. The origins of the discussion can be traced partly to the theory of media events by Dayan and Katz (1992), which, since then, has been broadened to include traumatic events (e.g. Couldry et al., 2010; Katz \& Liebes, 2007; Liebes, 1998; Sumiala, 2013). Professional media are not only seen as an important institution that provides moral orientation but also as a significant actor that shapes and influences the events themselves. Thus, the ritual practices of journalists affect the way in which the event is interpreted and responded to by the audience. In the case of violent attacks, traditional media construct a ritualised "time out" for the crisis (Liebes, 1998). During the time out, they suspend their daily routines and start to follow a script, which means switching off the traditional media flow and switching on the crisis mode.

According to Kunelius and Nossek (2008), professional media carry out both rational and symbolic dimensions during disruptive events. ${ }^{1}$ The rational dimension of communication is seen as part of the social practices and institutions of self-reflection and criticism in society. Rationalisation is produced by transmitting, broadcasting and distributing facts and information as well as creating graphs and timelines to construct a causal structure of the event (Kunelius \& Nossek, 2008). The symbolic dimension, for one, exists through the circulation of emotions, symbols and images, and it is related to the construction of shared feelings and community (Kunelius \& Nossek, 2008). These two dimensions are not mutually exclusive but, instead, are dynamically intertwined, interpreting and constructing separate and chaotic incidents into a chronological and affective event.

Furthermore, rituals that are played out in and via the media have the power to mobilise collective sentiments (Sumiala, 2013). By creating a shared experience for the members of a potential community, rituals mark a switch from the profane to the sacred. Importantly, they also facilitate the transformation of the public from passive bystanders into more involved participants (Morse, 2018).

\section{Rituals as coping practices}

Rituals are also essential practices for individuals during and after crises. Rituals are socially standardised and repetitive forms of action with symbolic meaning. In crises, these practices are applied by individuals and communities to cope with disruption and its consequences (Sumiala, 2013). Thus, rituals affect the way in which people experience and respond to interruptions in their everyday lives (Thornburg et al., 2007). Rothenbuhler (2010) stated that communicative rituals serve as repair work in traumatic events. Violent attacks seek to disrupt a sense of predictability and stability. The rupture in the communicatively constructed reality caused by the attack requires symbolic repair work. For Rothenbuhler, "[t]he ritual element of communication produces the tendency of communication to produce the world it claims to portray" (2010:39). Thus, the fabric of reality is constructed in the self-sustaining system of everyday communication.

Coping practices are related to the capacity to apply ideas that provide meaning for social life (Bhandari et al., 2011). This can be achieved by reconstituting old rituals or constructing new ones. In disaster sociology, coping is defined as the way in which 
individuals and groups interpret and respond to certain troubling situations and connect with the wider society (Bhandari et al., 2011; Tandoc Jr \& Takahashi, 2016). Drawing on previous research, Bhandari et al. (2011: 15) identified different human practices of coping: building awareness of vulnerability and disaster risk, accessing local knowledge and skills, mobilising existing human and non-human resources and strengthening social networks and support. Moreover, human responses to disaster include convergence and social interactions, comforting and eating with other people (Thornburg et al., 2007). These ritualised coping practices aim to provide stability amid chaos.

\section{Ritual roles of spectators}

Instead of actively coping in the midst of disruption, research on the media-related rituals of ordinary people has traditionally placed them in the moral roles of spectators and publics. This body of literature has focused on spectatorship, witnessing, mourning and grieving, which manifest themselves in various ways on digital platforms (e.g. Chouliaraki, 2013; Morse, 2018; Mortensen, 2015; Sumiala, 2013; Tikka \& Sumiala, 2014). These practices are intrinsically linked to questions of ethics in response to mediatised death and suffering, and they conceive the role of ordinary people as recipients of mediated violence and death. Media witnessing is about seeing and acknowledging the pain and suffering of a distant "other". It bears the idea that, once the suffering has been recognised, it exerts a moral imperative to respond (Boltanski, 1999; Chouliaraki, 2006). Thus, the role of the media witness entails a coercive dilemma: how to alleviate suffering that is far way. The adequate form of action has been a topic of vivid scholarly debate. Classic answers have ranged from letting oneself be burdened by the despair to paying for charity or speaking publicly about the situation (Boltanski, 1999; Chouliaraki, 2013).

The continuous development of communication technology has offered more promising active methods of engagement for ordinary people. The emerging digital technologies and networks continue to seek answers to the questions of how to respond to a crisis and how to relieve suffering. The aim is to enable ordinary people to mobilise and to act in crises and, consequently, to avoid the roles of "mere" moral spectators and witnesses. According to Michal Givoni (2016: 1028), new forms of public engagement in crises "[break] with a long tradition [. . . in which publics were allocated a critical moral function that consisted in consuming, interpreting and circulating reports on distant suffering". Correspondingly, it has been recognised that the technologisation of communication has implications for humanitarian actions (Chouliaraki, 2013), and it enables people to form digital volunteer networks with crisis response capabilities (Park $\&$ Johnston, 2017). These novel forms of active participation have revived conceptualisations, such as a new modality of publics, humanitarian crowds and digital volunteers (Givoni, 2016; Pantti et al., 2012; Park \& Johnston, 2017). What these conceptualisations all aim to capture is the shifting role of ordinary people from spectators of suffering to potentially active responders in times of crisis and disruption.

However, the existing research is lacking in connecting the ritual approach to this notion of ordinary people as digital volunteers. To establish this connection and extend our understanding of the ritualisation of citizens' crisis responses in the digital era, the next section presents Bennet and Segerberg's (2013) idea of connective action. 


\section{Connective action as a cultural practice}

In their book, The logic of connective action, Bennet and Segerberg (2013) analysed political action and organisational processes in complex citizen mobilisations in the digital age. The underpinning notion is that digital media play an increasing role in the mobilisation and organisation of different forms of political action, such as street demonstrations. This notion is linked to the rise of highly individualised global publics. These publics consist of a large number of people who, when experiencing a common issue or problem, may seek individualised ways of participating in social movements via digital media technologies. Instead of asking individuals to join an established collective ideology, as in more conventional social movements, connective action allows personal action frames that are flexible and inclusive of different personal causes (Bennet \& Segerberg, 2013). The concept of connective action thus refers to an individual's digitally networked action in social media by which they engage in different issues and concerns (Bennet \& Segerberg, 2013).

Furthermore, Bennet and Segerberg (2013) introduced a formulation of crowdenabled connective action that highlights the agency of ordinary people. Crowd-enabled connective action networks commonly come into existence as a response to certain external events, such as a crisis. They appear and come together without any leading or enabling organisational actors, and they are characterised as "dense, fine-grained networks of individuals in which digital media platforms are the most visible and integrative organisational mechanisms" (2013: 13). Thus, via digital connectivity, ordinary people can self-organise and connect with an event and with each other.

In the event of a violent attack, the shattering reality of others appears to us in and via the digital media environment. It also constructs a moral space and invites the possibility of responding to the suffering of others (Morse, 2018). I argue that this moral call to respond, embedded in the problematics of media witnessing and combined with digitally enabled connective action, constitutes evolving cultural practices performed by ordinary people in times of crises.

\section{Method and data}

Violent crises are time-intensive events, during which information circulates vividly through various platforms and sites, and an immediate response from ordinary social media users is common (Bruns \& Hanusch, 2017; Jin et al., 2014). This constructs a fluid research field beyond human perception. Therefore, this study consists of two empirical phases. In the first phase, the unfolding case was traced by means of digital media ethnography to provide an outline of the event, to gain an in-depth interpretation of the patterns of repetitive communication and to trace the ritual process. To mitigate the uncertainty caused by the research field in flux, the second phase focused on qualitative content analysis of the data to assess the ritual functions of this communication. I follow here the work of Kunelius and Nossek (2008) on rational and symbolic dimensions of media during crises.

A note on research ethics is needed here. As an acute crisis event in the digital age presents a research setting in which people participating in digital platforms are at their most vulnerable, several ethical issues emerge in relation to questions of privacy and consent (Crawford \& Finn, 2015). To protect the privacy of message senders and 
avoid the traceability of the messages and Twitter accounts through search engines (see Markham, 2012), all the quotes from tweets in this article are free translations from Swedish to English.

\section{Digital media ethnography}

Digital media ethnography is an emerging methodological approach that meets the contemporary mobile condition of social life (Caliandro, 2018; Hine, 2015). It is suitable for following and tracing a situation as it unfolds. The fieldwork practices in the case of the Stockholm terror attack consisted of participating in digital media platforms and tracking how different actors started to respond, report and make sense of the disruption that took place in Drottningatan. I paid special attention to the kinds of digital communication practices and connections that ordinary people carried out on Twitter as well as to how the online news sites, such as Dagens Nyheter, Expressen and The Local, reported the situation. The fieldwork included making notes about, collecting and saving these digital materials. Through digital media ethnography, the prescribed, recurring and formalised patterns of communication were detected.

\section{Content analysis}

In the second phase, a content analysis of the Twitter feed formed around the hashtag \#openstockholm was conducted. The aim was to investigate the identified patterns of crisis response in greater detail. The material was collected manually and saved during the period 7-21 April 2017 in a pdf format. This format is not ideal for further research processing, as it is difficult to convert into another format. Furthermore, digital data saved in this way (and virtually in any other way) are incomplete and broken (Pink et al., 2018), as they interrupt the liveness and interactive features in the flow of tweets. However, it was a readily available means to collect the data to "freeze" the movement of messages for the purposes of thematisation.

Here, the empirical focus is on the acute phase of the crisis event. This is connected to the idea of how to react to a crisis to reduce its impact and resume activity as soon as possible (Roux-Dufort, 2016). In the case of the Stockholm terror attack, the acute phase started with the truck attack at 2:53 p.m. and ended in the evening at around 8 p.m., at which time the city centre was reopened after the lockdown. The time frame of the acute phase outlines the analysis of the \#openstockholm data: the period of analysis started with Nguyen's first message sent at 4:44 p.m., when this hashtag was initiated for the purpose of offering shelter, and it ended at approximately 8 p.m., when messages about resuming public transport started to appear in the feed. ${ }^{2}$ To cover this time period, I chronologically analysed the 2,000 first messages of the Twitter feed created around the hashtag \#openstockholm.

While sensitised to the literature on rituals in crises, the inductive coding process remained open to embracing all potential forms of responses (Mayring, 2000). The analysis started with reading through the material and making notes to identify themes emerging from the data. After this reflective process, a coding scheme with 18 themes was formed, and each tweet in the data set was given an ID (see Table 1). 
Table 1. Themes of the coding scheme

\begin{tabular}{rll} 
& Theme & Explanation \\
\hline 1. & Shelter & Offering a safe place to stay and transportation \\
2. & Pride & Expressions of pride \\
4. & Sharing info \# & Sharing information about \#openstockholm \\
5. & \# & Asking others for a safe place to go or transportation \\
& & Tweeting only \#openstockholm (exists alone but also used for the \\
& & purposes of replying to another user, forwarding a message that \\
6. & Shelter RT & \#openstockholm) \\
7. & Solidarity & Expression of solidarity \\
8. & Instruction & Sharing information that helps others to know what to do \\
9. & Comment & General comment of the event \\
10. & Information & Information about the ongoing event \\
11. & Anger & Expression of hate and anger \\
12. & Safety check & Telling others that the sender of the message is ok \\
13. & Warning & Warning people not to share their personal information online \\
14. Own action & Telling others what the sender of the message is currently doing \\
15. Spreading rumour & Spreading false information \\
16. & Refuting rumour & Refuting false information \\
17. Other & Irrelevant message \\
18. & Not available & Tweet is not visible \\
\hline
\end{tabular}

Next, the content of the messages was analysed by hand and coded in an Excel spreadsheet. The themes were not exclusive, as they overlapped in some cases.

Figure 1. Distribution of the themes in the \#openstockholm feed (per cent)

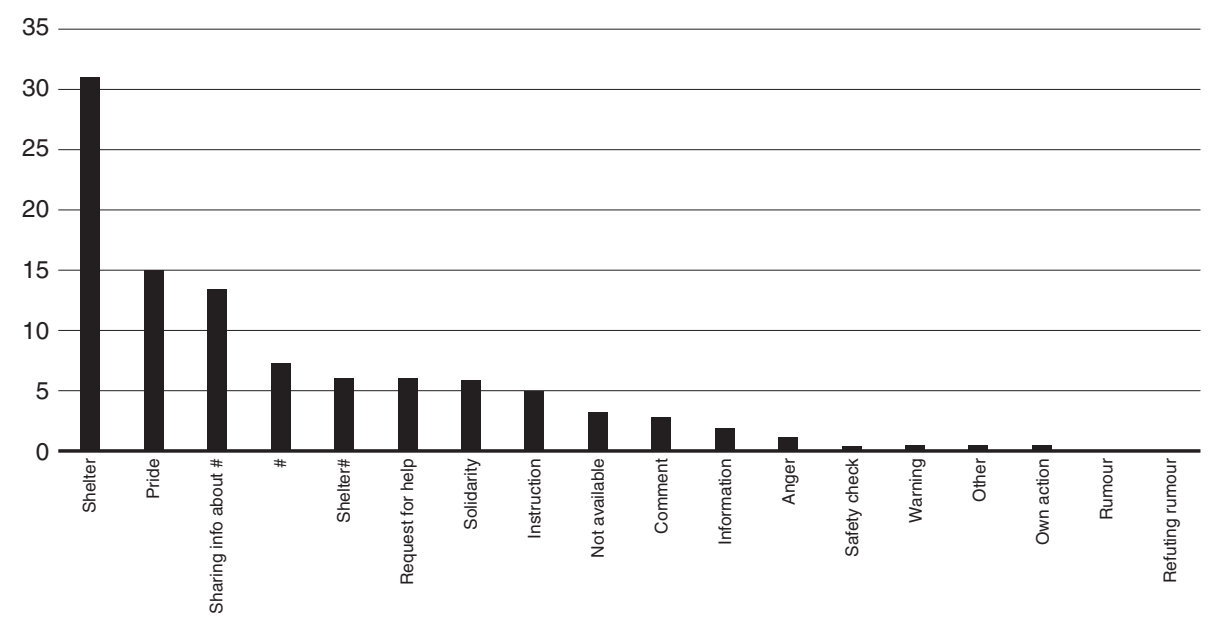

Comments: Only tweets from the acute phase are included. The number of coded themes is 2,095.

While the most frequently recurring theme in the \#openstockholm feed was offerings of aid, the hashtag was used for several other purposes as well, such as giving instructions 
and expressing pride. As Kunelius and Nossek (2008) suggested, media carry different dimensions in acute crisis events, both rational and symbolic. Notably, with regard to the analysed tweets, a clear majority $(71 \%)$ focused on rational responses; symbolic responses, thus, were in the minority $(22 \% ; 7 \%$ could not be decided). This may be considered as a crisis response performed by ordinary people that aims to rationalise an acute crisis event.

\section{Analysis}

\section{Ritualisation of open-door initiatives through a string of terror attacks}

While the hashtag \#openstockholm was initiated by a Swedish student, the idea did not come out of thin air. Instead, it was born on 13 November 2015, when a series of terror attacks occurred in Paris, causing the deaths of 130 people. Similar to the Stockholm crisis, the attacks and the ensuing massive security operation caused chaos and disarray in the streets of Paris. At that time, a freelance journalist, Silvain Lapoix, followed the unfolding event on social media. As a response, he then tweeted, "Those who can open their doors, geotag your tweets and [use] \#PorteOuverte to indicate safe places" (Varagur, 2015). The hashtag took off, and it was used widely to offer shelter to those in need.

As Bennet and Segerberg (2013) suggested, crowd-enabled connective action networks emerge as a response to external events. After the November 2015 Paris terror attacks, similar aid networks of digitally connected ordinary people became a recurring phenomenon. Different variations of the hashtag by which people have connected to offer shelter to those affected by a violent attack have since appeared in several cases: Brussels in March 2016, \#openhouse; Nice in July 2016, \#opendoors; Munich in July 2016, \#offenetür; Manchester in May 2017, \#roomformanchester; Stockholm in April 2017, \#openstockholm; and Barcelona in April 2017, \#bedinbarcelona.

Consequently, as a response to the terror attack in Stockholm, the hashtag \#openstockholm quickly attracted significant engagement on Twitter. Nguyen's messages were retweeted and liked hundreds of times, and people started to use the hashtag to allow those affected by the tragedy to find safety and refuge. Thus, Nguyen's message initiated a hasty mobilisation of aid, connecting thousands of ordinary people who formed an action network as a response to witnessing the plight of others (cf. Bennet $\&$ Segerberg, 2013). What is noteworthy here is that, although some Swedish officials and companies engaged with the hashtag later on that evening, it was initiated by an ordinary individual witnessing the crisis, and the most prominent users were ordinary people with no professional role in the crisis event.

As described above, these crowd-enabled connective action initiatives have become socially standardised, repetitive and patterned performances (cf. Grimes, 2011), in which Twitter is the most integrative organisational mechanism (cf. Bennet \& Segerberg, 2013). To follow the literature on rituals (e.g. Grimes, 2011; Sumiala, 2013), I claim that "open-door initiatives" serve as a ritualised crisis communication of ordinary people. Since the November 2015 Paris terror attacks, open-door initiatives have become a prescribed and formalised crisis response practice that connects people in the midst of crisis through repetitive participation. This practice becomes more salient each time an open-door initiative is implemented through ordinary media users in the cities of Europe 
when they are targets of violent attacks. Consequently, it has developed as part of our collective imagination (e.g. Sumiala, 2013).

\section{Ritual functions of \#openstockholm: organise chaos and construct community}

What, then, is the social purpose of this ritualised crisis response in the case of \#openstockholm? In the vocabulary of Kunelius and Nossek (2008), media rationalise crisis events by distributing facts and constructing timelines. Rationalisation is also emphasised in organisational crisis communication research. Crisis managers are urged to provide instructing information whereby people "are told what to do to protect themselves physically" (Coombs, 2012: 146-147). In the \#openstockholm data, the majority (71\%) of the messages aimed to rationalise the event through practical instructions and the construction of facts and timelines.

The vast majority of the messages were aimed at physical protection and coping in the situation (cf. Thornburg et al., 2007), as people offered and requested shelter and transportation and disseminated these messages. The key actors were local people who invited those stranded to come over and have something to eat and drink: "Welcome to my place near Saint Eriksplan. We have wine, coffee, buns, bed, couch and company." Messages typically included information about the location of the message sender and a description of how many people could be accommodated: "There is place and food for 4 to 5 persons in Bromma if someone needs. DM for address." To enable contact, these messages also included guidance for replying. The most common guide for getting in touch was direct messaging (DM), but occasionally people also included their personal information in the tweets, such as their phone number, exact street address or e-mail address.

However, the ways in which individuals engaged with this ritualised crisis response demonstrate the agile character of crowd-enabled connective action. Besides offering safe places to stay, the initiative rapidly adapted to the other effects of the ongoing situation. The lockdown of public transportation affected the area surrounding Stockholm's city centre and caused massive queues for taxis, particularly at Arlanda Airport. Thus, people also started offering transportation and used the hashtag to inform others about their routes, timing and destinations of conveyance: "Somebody in need of ride to Vaxholm? We are close to Norrtull just now."

The technological affordances of Twitter enable people to remediate content easily. In accordance with this social media logic, people actively shared all these offers for safe places and transportation in the forms of retweets and screenshots. One Twitter user, for example, wrote, "Friends, if you are in Stockholm and in need of help, check \#openstockholm." As a response, those affected by the attack soon started to use the hashtag to request aid, shelter and transportation: "Someone in Flemmingberg who could offer place?"

The rationalisation of the acute crisis event also functioned by giving and sharing instructions and information. These messages concerned diverse issues, ranging from operating boat and bus lines to helping children: "If you see a child on her own, lend your phone and help them. Many parents working in the city can't leave." One recurrent suggestion was to open a Wi-Fi connection for public use to relieve the pressure on mobile phone networks, which were overloaded by the situation. Several users also 
advised people not to share graphic images of victims, not to spread rumours and to stay away from central parts of Stockholm. The event information that was shared was often originally produced by local news media, such as Dagens Nyheter and Mitt i Stockholm, or the local authorities. These tweets constructed an updating of the timeline of the event. For example, one user tweeted: "3 persons dead, 8 injured. No confirmed information about shootings. No offenders arrested."

The repetitive participation in the production, sharing and dissemination of these instructions and information organised the rumour-filled chaos into a chronological event (cf. Kunelius \& Nossek, 2008). Simultaneously, the rational became ritualised. Accordingly, the ritualised crisis communication of ordinary people operated as a coping practice, providing stability for those affected by the disruption (Thornburg et al., 2007).

Acute crisis events also invite public displays of emotion, which Kunelius and Nossek (2008) addressed as the symbolic dimension of media. In the \#openstockholm data, 22 per cent of the messages were symbolic expressions of pride and solidarity. These emotions were evoked by witnessing the terror attack and the pain of its victims but even more so by the actions of ordinary people striving to provide protection for each other. In these messages, expressions of pride and admiration were associated with the people who welcomed those affected by the crisis to their homes. This was explicitly stated in several messages, as follows: "Proud of you who are opening homes." In many messages, these positive feelings were elevated to concern the whole nation of Sweden: "So proud of this country." Here, the emotional display turned away from disruption and towards cohesion and resilience. The messages of solidarity, for one, were constructed by emoji strings of hearts, sad faces and praying hands as well as chains of hashtags, such as \#prayforsweden and \#prayforstockholm. The symbolic responses illustrate how ordinary people aimed to comfort and encourage each other to cope with the consequences of the attack (Bhandari et al., 2011). Hence, the ritual function of these symbolic tweets was the mobilisation of collective sentiments, reinforcement of the shared experience and construction of community (cf. Kunelius \& Nossek, 2008; Sumiala, 2013).

\section{Ordinary people as ritualised first responders}

The hashtag \#openstockholm and the related examples appeared along with the presence of violent public deaths and the danger of further loss. Ritualised crisis communication on Twitter connected ordinary people around the same cause. Thus, the \#openstockholm initiative marked the Stockholm terror attack as a symbolically significant event. Importantly, it enabled the transformation of the public from spectators and witnesses into involved participants (cf. Morse, 2018). Drawing on the notion of the transformative power of rituals (e.g. Sumiala 2013), I argue that communication in, and via, the opendoor initiative represents a reconfiguration of the ritualised practices of ordinary people in times of crisis, thus contributing to the transformation of their ritual roles. In addition to consuming, witnessing, commenting on and circulating mediated testimonies on the unfolding events (cf. Chouliaraki, 2013), local citizens are able to mobilise networks of aid and actually help those in need through the rituals of connective action. This means that they are able to cross the line between spectatorship and disaster relief and, consequently, transform their roles from passive audience members into active agents (cf. Givoni, 2016). Through ritualised participation in this crowd-enabled connective action, 
ordinary media users can extend their roles towards the traditional field of authority and to act as first responders in a crisis. This again poses questions regarding the roles of the authorities that are responsible for public safety. Thus, we can ask whether these open-door initiatives are challenging or downplaying the roles and responsibilities of authorities during acute crisis events.

\section{Ritualisation of the crisis response contributes to ephemeral social cohesion}

Some studies have suggested that a widespread and persistent assumption exists among officials, humanitarians and the media that, in crises, ordinary people are helpless, panicstricken and dependent on the intervention of official agencies (Fischer, 1998; Givoni, 2016). However, the empirical analysis of \#openstockholm suggests otherwise. I argue that the crisis communication of ordinary people is ritualised via repetitive participation in open-door initiatives in the context of terror attacks. The ritualised connective action related to \#openstockholm aimed to protect and comfort those in need of help. Moreover, it highlights the role of ordinary people in the field of crisis response and public safety and potentially mediates the outcomes of a crisis.

As maintained above, rituals shape the way in which people interpret and respond to a crisis (Sumiala, 2013; Thornburg et al., 2007). As is the case with the ritual practices of professional media (e.g. Liebes, 1998), the ritualised connective actions of ordinary people affect the public's experience of a crisis. The implementation of the open-door initiative from our collective imagination had an impact on people's reactions and understanding of the Stockholm terror attack by marking it as a symbolically significant event. To follow Rothenbuhler's (2010) insight that ritual communication tends to produce the world that it claims to display, I contend that the ritualised crisis communication of ordinary people served as repair work, aiming to restore the predictability of everyday life. The circulation of offerings of shelter and feelings of pride and solidarity strengthened the community's positive image of itself as a competent and compassionate actor in the midst of a terror attack (cf. Rothenbuhler, 2010).

Lilie Chouliaraki (2013), a scholar of mediated suffering, asked what the moral implications are when actions that aim to relieve the suffering of others are increasingly intertwined with digital communication technology. She settled on "sceptical optimism" by noting that "new media may habituate us into mundane cosmopolitanizing acts, by enabling us to get selectively engaged with momentary but efficient form of online activism" (2013: 18). In line with Chouliaraki's insight, I contend that the ritualised connective action powerfully contributed to helping others during the acute phase of the crisis event. However, as the perpetrator was captured and the city started to recover from the shock caused by the terror attack, the hashtag was taken over by users promoting Islamophobia and anti-immigration opinions (Al-Saqaf \& Christensen, 2017). Thus, the temporality of togetherness and efficient action is, indeed, fleeting and ephemeral. Nevertheless, the spatial dimension of help is local rather than cosmopolitan. Hereby, \#openstockholm departed from the promises of digital humanitarianism, whereby technologically savvy volunteers from around the world relieve the pain of distant others (cf. Givoni, 2016). In this analysis of \#openstockholm, we could see that ritualised crisis communication enabled local people to help those inhabiting the same spatial location in 
an area of Stockholm and, thus, effectively participated in the alleviation of proximate suffering. Hence, \#openstockholm offered ordinary people an ethical way to respond to mediatised death and suffering and thus meet the moral imperative to alleviate the plight of others. I contend that the ritualised crisis response of ordinary people related to \#openstockholm contributed, if only ephemerally, to the resilience and social cohesion of the community and thus helped the community to lessen the damage inflicted.

A ritual approach to the crisis response practices of ordinary people complements the top-down crisis communication research by providing a more nuanced understanding of citizens' roles, not only as stakeholders and publics of organisations (cf. Holmgreen, 2015; Jin et al., 2014) but also as active agents of society with crisis response capacities. The main limitation of the chosen research design is that the analytical reading of the case relies on media representations. The personal motivations of ordinary individuals to participate in \#openstockholm therefore remain imprecise. Thus, this study could be complemented by interviews or surveys. Nevertheless, as acute crisis events are unpredictable by definition (Coombs, 2012), digital media ethnography combined with content analysis is an advantageous method to track and trace the fluidity of unexpected events. A challenge for future research could be to expand ways to think of the role of digitally connected ordinary people in crises as well as to provide methodological tools to capture and analyse these time-intensive events in a digital media environment.

\section{Funding}

This work was supported by Koneen Säätiö (Kone Foundation).

\section{Notes}

1. Kunelius and Nossek (2008) used the terms "ritual dimension" and "rational dimension" in their article. However, to avoid confusion, I have replaced the term "ritual" here with the term "symbolic".

2. The hashtag \#openstockholm was already in use before the attack, referring to open data of the city of Stockholm.

\section{References}

Al-Saqaf, W. \& Christensen, C. (2017). So was Twitter used at the truck attack in Stockholm. Paper presented at the conference Journalism in a World of Terrorism, 2017, May 9-11 at Linneaus University, Fojo Media Institute and Institution for Media and Journalism.

Bennet, L. W. \& Segerberg, A. (2013). The logic of connective action: Digital media and the personalization of contentious politics. New York: Cambridge University Press.

Bhandari, R. B., Okada, N. \& Knotterus, David J. (2011). Urban ritual events and coping with disaster risk: A case study of Lalitpur, Nepal. Journal of Applied Social Science, 5(2): 13-32.

Boltanski, L. (1999). Distant suffering: Politics, morality and the media. Cambridge: Cambridge University Press.

Bruns, A. \& Hanusch, F. (2017). Conflict imagery in a connective environment: Audiovisual content on Twitter following the 2015/2016 terror attack in Paris and Brussels. Media, Culture \& Society, 39(8): 1122-1141.

Caliandro, A. (2018). Digital methods for ethnography: Analytical concepts for ethnographers exploring social media environments. Journal of Contemporary Ethnography, 47(5): 551-578.

Chouliaraki, L. (2006). The spectatorship of suffering. London: Sage.

Chouliaraki, L. (2013). The ironic spectator: Solidarity in the age of post-humanitarianism. Cambridge: Polity Press.

Coombs, T. W. (2012). Ongoing crisis communication: Planning, managing, and responding (3rd ed.). Thousand Oaks, CA, London: Sage. 
Cottle, S. (2014). Rethinking media and disasters in a global age: What's changed and why it matters. Media, War \& Conflict, 7(1): 3-22.

Couldry, N. (2012). Media, society, world: Social theory and digital media practice. Cambridge: Polity Press.

Couldry, N., Hepp, A. \& Krotz, F. (eds.) (2010). Media events in a global age. Abingdon: Routledge.

Crawford, K. \& Finn, M. (2015). The limits of crisis data: Analytical and ethical challenges of using social and mobile data to understand disasters. GeoJournal, 80: 491-502.

Crowe, A. (2012). Disasters 2.0: The application of social media systems for modern emergency management. Boca Raton: Taylor \& Francis.

Dayan, D. \& Katz, E. (1992). Media events: The live broadcasting of history. Cambridge: Harvard University Press.

Fischer, H. (1998). Response to disaster. Oxford: University Press of America.

Givoni, M. (2016). Between micro mappers and missing maps: Digital humanitarianism and the politics of material participation in disaster response. Environment and Planning D: Society and Space, 34(6): 1025-1043.

Grimes, R. L. (2011). Ritual, media and conflict: An introduction. In R. L. Grimes, U. Hüsken, U. Simon, \& E. Venbrux (eds.), Ritual, media, and conflict (pp. 3-33). New York: Oxford University Press.

Hine, C. (2015). Ethnography for the internet: Embedded, embodied and everyday. London: Bloomsbury Publishing.

Hjarvard, S., Mortensen, M. \& Eskjaer, M. F. (2015). Introduction: Three dynamics of mediatized conflicts. In M. F. Eskjaer, S. Hjarvard \& M. Mortensen (eds.), Dynamics of mediatized conflicts (pp. 1-30). New York: Peter Lang Publishing.

Holmgreen, L. -L. (2015). "Why am I to blame when the law is on my side?" A study of crises, public opinion and frames. On the Horizon, 23(4): 363-373.

International Federation of Red Cross and Red Crescent Societies. (2013). World disaster report 2013. Imprimerie Chirat: Lyon, France.

Jin, Y., Liu, B. F. \& Austin, L. L. (2014). Examining the role of social media in effective crisis management: The effects of crisis origin, information form, and source on publics' crisis responses. Communication Research, 41(1): 74-94.

Katz, E. \& Liebes, T. (2007). No more peace! How disaster, terror and war have upstaged media events. International Journal of Communication, 1: 157-166.

Kunelius, R. \& Nossek, H. (2008). Between the ritual and the rational: From media events to moments of global public spheres? In E. Eide, R. Kunelius \& A. Phillips (eds.), Transnational media events. The Mohammed cartoons and the imagined clash of civilizations (pp. 253-273). Göteborg: Nordicom.

Liebes, T. (1998). Television's disaster marathons: A danger for democratic processes? In T. Liebes \& J. Curran (eds.), Media, ritual and identity (pp. 71-84). London: Routledge.

Markham, A. N. (2012). Fabrication as ethical practice. Information, Communication and Society, 15(3): 334-353.

Mayring, P. (2000). Qualitative content analysis. Forum: Qualitative Social Research, 1(2).

Mediepodden (2017, April 13). Avsnitt 34: Mediernas hantering av terrorattacken i Stockholm [Section 34: Media managing the terror attack in Stockholm]. Mediepodden [online]. Retrieved from http://mediepodden.se/ sasong-2/avsnitt-34-mediernas-hantering-av-terrorattacken-i-stockholm/ [accessed 2017, December 11].

Morse, T. (2018). The construction of grievable death: Toward an analytical framework for the study of mediatized death. European Journal of Cultural Studies, 21(2): 242-258.

Mortensen, M. (2015). Connective witnessing: Reconfiguring the relationship between the individual and the collective. Information, Communication \& Society, 18(11): 1393-1406.

Murthy, D. (2012). Towards a sociological understanding of social media: Theorizing Twitter. Sociology, 46(6): 1059-1073.

Murthy, D. \& Gross, A. J. (2017). Social media processes in disasters: Implications of emergent technology use. Social Science Research, 63: 356-370.

Pantti, M. \& Tikka, M. (2014). Cosmopolitan empathy and user-generated disaster appeal videos on YouTube. In T. Benski \& E. Fisher (eds.), Internet and emotions (pp. 178-192). New York: Routledge.

Pantti, M., Wahl-Jorgensen, K. \& Cottle, S. (2012). Disasters and the media. New York: Peter Lang.

Park, C. H. \& Johnston, E. W. (2017). A framework for analyzing digital volunteer contributions in emergent crisis response efforts. New Media \& Society, 19(8): 1308-1327.

Pink, S., Ruckenstein, M., Willim, R. \& Duque, M. (2018). Broken data: Conceptualising data in an emerging world. Big Data \& Society, 5(1): 1-13.

Rothenbuhler, E. W. (2010). Media events in the age of terrorism and the internet. Romanian Review of Journalism and Communication, 4(2): 34-41.

Roux-Dufort, C. (2016). Delving into the roots of crises. The genealogy of surprise. In A. Schwarz, M. W. Seeger \& C. Auer (eds.), The handbook of international crisis communication (pp. 24-33). Chichester: John Wiley \& Sons, Inc. 


\section{Minttu Tikka}

Schwarz, A., Seeger, M. W. \& Auer, C. (2016). Significance and structure of international risk and crisis communication research: Toward an integrative approach. In A. Schwarz, M. W. Seeger \& C. Auer (eds.), The handbook of international crisis communication (pp. 1-65). Chichester: John Wiley \& Sons, Inc.

Starbird, K. \& Palen, L. (2010). Pass it on? Retweeting in mass emergency. Paper presented at the proceedings of the conference $7^{\text {th }}$ International ISCRAM, 2010, May 2-5, Seattle, USA.

Sumiala, J. (2013). Media and ritual: Death, community and everyday life. Routledge: New York.

Sumiala, J. \& Tikka, M. (2011). Reality on circulation - School shootings, ritualised communication, and the dark side of the sacred. ESSACHESS. Journal for Communication Studies, 4(8): 145-159.

Sumiala, J., Valaskivi, K., Tikka, M. \& Huhtamäki, J. (2018). Hybrid media events: The Charlie Hebdo attacks and global circulation of terrorist violence. Bingley: Emerald.

Takahashi, B., Tandoc Jr, E. C. \& Carmichael, C. (2015). Communicating on Twitter during a disaster: An analysis of tweets during Typhoon Haiyan in the Philippines. Computers in Human Behavior, 50: 392-398.

Tandoc Jr, E. C. \& Takahashi, B. (2016). Log in if you survived: Collective coping on social media in the aftermath of Typhoon Hayan in the Philippines. New Media \& Society, 19(11): 1778-1793.

The Local. (2017, April 7). Sweden tightens borders as police make one arrest after truck attack. The Local [online]. Retrieved from https://www.thelocal.se/20170407/live-truck-drives-into-crowd-on-busystockholm-street [accessed 2017, December 8].

Thornburg, P. A., Knotterus, D. J. \& Webb, G. R. (2007). Disaster and deritualization: A reinterpretation of findings from early disaster research. Social Science Journal, 44: 161-166.

Tierney, K. J. (2007). From the margins to the mainstream? Disaster research at the crossroads. Annual Review of Sociology, 33: 503-525.

Tikka, M. \& Sumiala, J. (2014). Media witnessing on YouTube: Rethinking crisis in a mediatized condition. In K. Loftsdóttir \& L. Jensen (eds.), Crisis in the Nordic nations and beyond (pp. 9-30). Surrey: Ashgate.

Turner, G. (2010). Ordinary people and the media: The demotic turn. London: Sage

United Nations Foundation. (2011). Disaster relief 2.0. The future of information sharing in humanitarian emergencies. Retrieved from: http:/www.unfoundation.org/assets/pdf/disaster-relief-20-report.pdf

Varagur, K. (2015, 17 November). Meet the man behind the hashtag Parisians used to find shelter. Huffington Post [online]. Retrieved from https://www.huffingtonpost.com/entry/sylvain-lepoix-porteouverte us_564b4609e4b045bf3df0cae0?guccounter=1\&guce_referrer_us=aHR0cHM6Ly93d3cuZ29vZ2x1LmNvbS8\&guce_referrer_cs=SgHn7fpzPEe_iOgNzSjluA [accessed 2019, March 3]. 